\title{
Trabajo Social en el campo de la salud mental. La discusión sobre el diagnóstico*
}

Social Work in the field of mental health. The debate on diagnosis

\author{
Rubens R. Méndez ${ }^{* *}$ \\ Damian A. Wraage ${ }^{* * *}$ \\ María Ana Costa****
}

\section{Resumen}

Afirmamos que nuestra participación en el campo de la salud mental no es por una generosa invitación de otras disciplinas, en este caso la psiquiatría, sino por la necesidad que el campo tiene de integrar lo que el trabajo social "sabe hacer". El lugar donde se forma el objeto -locura- es un lugar donde se conjugan procesos económico-sociales (la sociedad del trabajo, la lucha contra los no proletarios), reglamentaciones institucionales (necesidad del encierro del otro, del diferente), resoluciones judiciales (penalización de la pobreza y las familias llamadas disfuncionales), disposiciones administrativas (control de la población), estudios sobre el comportamiento (gnoseología sobre la enfermedad mental, DSM), todo lo cual constituye la red de emergencia que da como resultado la aparición de ese objeto. Es decir, el objeto del campo no es producto del desenvolvimiento de una disciplina, la psiquiatría, sino de "la formación de

* Este trabajo se elaboró a partir del avance del proyecto "Trabajo social en el campo de la salud mental. La intervención social a la luz del Artículo 12 de la Convención sobre los Derechos de las Personas con Discapacidad", presentado y aprobado por la Facultad de Ciencias de la Salud y Servicio Social (SAL 079/11) y la Universidad Nacional de Mar del Plata (15/I074). República Argentina.

Para la redacción de este artículo se contó con la colaboración de las licenciadas en Servicio Social María Celeste Camou, María Victoria Martinucci, Natalia Fainburg y María Angeloni, así como de la Profesora de Filosofía Marina Bolgeri y la becaria de investigación Gabriela Bru.

${ }^{* *}$ Licenciado en Servicio Social. Profesor Titular. Universidad Nacional de Mar del Plata. Investigador Principal. Correo electrónico: rrmendez@mdp.edu.ar

${ }^{* * *}$ Licenciado en Servicio Social. Profesor Adjunto. Universidad Nacional de Mar del Plata. Investigador Principal. Correo electrónico: dawraage@hotmail.com

${ }^{* * * * *}$ Licenciada en Servicio Social. Jefa de Trabajos Prácticos. Universidad Nacional de Mar del Plata. Investigadora Principal. Correo electrónico: mariaanacosta@hotmail.com.

Artículo tipo 1: de investigación científica.

Recibido: 10 de febrero de 2012 Aprobado:7 de marzo de 2012 
ciertos y determinados dominios de saber a partir de relaciones de fuerza y relaciones políticas en la sociedad" (Foucault. 2003) en las cuales el trabajo social también participa.

En cualquier actividad científica grupal institucionalizada, el diagnóstico se funcionaliza como una base comunicacional entre sus miembros, $\mathrm{y}$ en esta discusión el trabajo social tiene algo que decir.

Palabras claves: trabajo social, salud mental, régimen de verdad, diagnóstico clínico, diagnóstico social.

\section{Abstract}

We claim that our participation in the field of mental health does not exist by a generous invitation of other disciplines, in this case psychiatry, but because the field needs to integrate the "know how" of social work.

The place where the concept of "madness" is produced includes socioeconomic processes (labor society, the fight against no-proletariat), institutional rules (the need to confine the other, the "different"), legal resolutions (penalization of poverty and the so-called "non-functional" families), administrative regulations (control of population), behavior studies (gnoseology of mental illness, MHD), thus forming an emergency net that results in that object. So the field object does not result from the development of a discipline-psychiatry-but from "the creation of singular ways of dominion among knowledge, from force relations and political relations in society" (Foucault, 2003), where social work also participates.

In every scientific or institutional activity, diagnosis is built up as a result of communication among its members, and in this debate social work has something to say.

Keywords: social work, mental health, regime of true, clinical diagnosis, social diagnosis.

Sumario: 1. introducción, 2. Desarrollo, 3. La cuestión, 4. Conclusión y 5. Referencias bibliográficas. 


\section{Introducción}

La intervención social en el campo de la salud mental fue una de las primeras prácticas que realizó el trabajo social desde sus orígenes, ya que, como planteaba Mary Richmond en Social Diagnosis (1917: 434), "la insania y la debilidad mental nos llevan más lejos aún de lo que nos lleva el alcoholismo, a internarnos en el territorio en el cual los datos médicos y los sociales no se pueden separar tácitamente".

Los trabajadores sociales estamos cotidianamente vinculados con las personas que sufren padecimiento mental, precisamente en el ámbito donde se dialoga y se discute sobre la experiencia que ellos hacen, que ellos tienen, de su propia existencia. Esto nos introduce en la discusión sobre las capacidades que poseen las personas con padecimiento mental, o, deberíamos decir, las capacidades que tienen aun con padecimiento mental. Y éste no es cualquier lugar, pues es el lugar donde la persona trata de afrontar la realidad y significar el mundo, su presente y sus obras. Más allá de tomar esta realidad desde una forma limitada o incompleta, es la forma que esta persona utiliza para comunicarse con el mundo y comunicar al mundo lo que ella es, proyecta y hace (Méndez, 2006).

Baudrillard afirmaba que en esta era el sistema se reproducía a través de la imposición de un código que era el que establecía una "estrategia hecha de distinciones, separaciones, discriminaciones, oposiciones estructurales y jerarquizadas" (Baudrillard, 1984: 32) que "licenciaba categorías enteras de la sociedad". Por ello expresaba que la lucha no se basaba solamente en la apropiación de la plusvalía, sino en las formas que toma el código que se nos impone. Sin duda, si esta forma de comprensión se propone para toda la sociedad, entenderemos que el impacto es mucho más concreto en el segmento poblacional que padece alguna discapacidad.

En forma pertinaz y obstinada, la sociedad sigue presentando actores que una y otra vez reclaman una parte impensada y no consensuada previamente de participación, de existencia, en lo ya instituido como lo común. Actores colectivos que establecen una disrupción en el paisaje social, que proponen la distorsión -en este caso las personas o los grupos que trabajan en la discapacidad-son parte de esta dramatización. Con su 
aparición, estas personas o grupos preguntan al Estado si la condición de desocupados los priva de la condición de ciudadanía, si el Estado tiene como necesidad la existencia de personas con discapacidad, si las condiciones de igualdad que da la ciudadanía existen realmente para las personas con discapacidad, si el derecho de las personas con discapacidad es el mismo derecho que tienen los ciudadanos que no lo son. En resumen: las personas con discapacidad o los grupos que trabajan en la discapacidad traen el litigio de la diferencia en la inscripción ante la ley, mostrando que existen grandes espacios donde la desigualdad es la ley. De esta manera, lo que estos movimientos sociales traen a la superficie social es el hecho de que existen grandes sectores poblacionales para los cuales es difícil comprometerse o cumplir con lo que las instituciones o el marco legal les impone, si se sienten cotidianamente fuera de ese marco legal o, lo que es peor, si creen que ese marco legal les produce mayor sufrimiento.

Sobre estas cuestiones, Roberto Gargarella (2005), como hombre del derecho, ofrece algunas consideraciones, para lo cual trabaja sobre el horizonte de la pobreza que castiga a grandes sectores poblacionales, y por ello trata de construir una forma de comprensión sobre la posibilidad legítima que esos sectores tienen para plantear la resistencia al derecho. En nuestro caso, nos parece importante explorar otro concepto que propone Gargarella, el de "alienación legal”. Para el autor, la falta del cumplimiento de derechos humanos básicos por parte de la autoridad estatal, o de las instituciones que la componen, significa la instauración de una alienación legal para amplios sectores de la población; esta alienación, a su vez, habilita a estos sectores para resistir al derecho. El autor afirma que elige el término alineación para rescatar el hecho de que esos sectores sociales "viven" a las normas como extrañas a ellos, porque las sufren o son afectados por su aplicación y porque fueron ajenos a su formulación. Es decir, Gargarella parece reconocer que la alienación legal no sólo consiste en la falta o la inexistencia de un adecuado marco legal que proteja a estos sectores, sino que también es alienación en tanto esos sectores son víctimas de la existencia de "normas ajenas" a ellos.

Entonces la pregunta es: ¿hay segmentos de nuestra población que están privados de un adecuado marco legal que los proteja y por ello están 
expuestos a la violencia, o en realidad esos sectores sufren un marco legal, que es aquel que los violenta?

Giorgio Agamben (2007), cuando expresa su concepto de "estado de excepción", pone bajo la lupa el tema de los momentos en los cuales se suspende el derecho, pero precisamente para garantizar su existencia y su permanencia. Para el autor, este estado, que debería ser provisorio, se convirtió desde el siglo XX en la forma permanente y "paradigmática" de gobierno. Las democracias se han vuelto más dependientes de lo que sus "ejecutivos" deciden, y a la vez menos parlamentarias (en nuestro país esto se puede ver claramente en la utilización de los denominados "superpoderes" que quedan librados a la discrecionalidad del Poder Ejecutivo). En este sentido, Agamben expresa que no es la confusión de los poderes lo que le interesa sobre el estado de excepción, sino el aislamiento de la "fuerza-de-ley", de la ley. Él define un "estado de la ley", en el cual, por un lado, la norma está vigente pero no se aplica (no tiene "fuerza") y, por otro, actos que no tienen valor de ley adquieren la "fuerza" (en el caso de la discapacidad en su conjunto, es cotidiana la observación de la "no aplicación de la ley", muchas veces por la "aplicación" de reglamentos o normas menores que sí tienen "fuerza de ley").

A esta discusión se suma Judith Butler, específicamente en sus obras Vida precaria. El poder del duelo y la violencia (2006) y ¿Quién le canta al Estado-Nación? Lenguaje, política, pertenencia (2009), cuando expone sus dudas sobre algunas cuestiones que plantea Hannah Arendt en La condición humana (1998). Específicamente cuando Arendt establece que la política se define como una actividad que se desarrolla en la esfera pública según el modelo de la ciudad-estado griega, dejando fuera de la política a quienes estaban en el campo de lo privado y que a su vez se encargaban de la reproducción de la vida material de la comunidad (mujeres, niños, esclavos y los privados de derecho [como las personas con discapacidad]). Butler, si bien plantea su desacuerdo, considera que esta visión, que significa la exclusión de la política de todos aquellos que por su edad, género, raza, nacionalidad y estatus laboral [también personas con discapacidad, agregamos nosotros] que se los descalifica para la ciudadanía, se reactualiza en los Estados modernos. Sin embargo, 
el giro que da la autora está dado en el hecho por el cual para ella, al mismo momento en que se los descalifica, se los "califica activamente" para convertirse en "sin-estado". Es decir, es el mismo momento el que los priva de la ciudadanía y el que los "dota de un estatus y se los prepara para ser desposeídos y desplazados."

Esta desposesión es una actividad política del Estado por la cual a grupos enteros de la población se los desafilia del marco jurídico, pero integrándolos a otras relaciones de poder, como las provistas por la forma de intervención en salud mental.

Sabemos que el Estado no agota su poder en el ejercicio del derecho, $\mathrm{y}$ es por ello que tiene la posibilidad de suspender ese marco jurídico a favor de la instauración de un conjunto de normas administrativas que refuerzan su poder soberano, como lo es en la detención involuntaria por averiguación de antecedentes, la hospitalización involuntaria, los llamados códigos de convivencia o edictos, y también en el caso de las políticas sociales.

El marco jurídico de nuestro país establece un número de derechos humanos de los que todos los ciudadanos de la nación pueden gozar. Sin embargo, las políticas sociales que ese Estado crea para, en teoría, lograr la satisfacción de esos derechos humanos, son un conjunto de normas que, en forma arbitraria y completamente discrecional, son ejercidas por funcionarios que utilizan una resolución ejecutiva, con fuerza de ley, por sobre la ley; que de esta manera queda momentáneamente suspendida (existen innumerables ejemplos como el de los derechos laborales o la obligación del cupo laboral para personas con discapacidad, la falta de exención de impuestos y tasas a organizaciones de personas con discapacidad, la utilización del derecho a una pensión para clasificar la discapacidad, la falta de recursos económicos por la "doble imposición", etc.).

La política social que es vivida por los sectores sociales como ausente o insuficiente para cubrir sus derechos mínimos, y por ello se vive como alienante, en realidad es un instrumento que crea personas en estado de privación. Es una herramienta por la cual se establece todo un entramado de normas y disposiciones sobre los sectores más desfavorecidos, que significa una saturación de poder sobre ellos. 
En la mayoría de los casos de los sectores sociales que ingresan en el campo de las políticas sociales, se asiste a un vasto despliegue de intervención del poder público sobre la organización privada de esos sectores, sostenida en innumerables instituciones. Son las instituciones locales las que determinan cuáles comportamientos son los adecuados, cuáles son las formas aceptadas de asociatividad, cuáles son las formas de dar la lucha política o de llevar adelante los vínculos; en definitiva, establecen cómo debe ser una vida social para ser reconocida dentro del marco jurídico. Es por ello que el denominado Ingreso Universal para la Niñez no es universal; que la posibilidad de acceso a una pensión graciable para las personas con discapacidad no es para todos los discapacitados; que el pase gratuito de transporte público para personas con discapacidad no se puede utilizar como tal; que los planes de vivienda para personas sin vivienda no son utilizados por personas sin vivienda. Porque desde las instituciones capilares de la administración del Estado se crean y ejecutan disposiciones que deben ser cumplidas por los "supuestos beneficiarios de la ley", a tal punto que suspenden la aplicación efectiva de esta última.

Un capítulo de nuestra investigación contempla la realización de diferentes triangulaciones entre el "estado de excepción", la "saturación de poder" y la "gubernamentalidad", para observar hasta qué punto los métodos de desafiliación de sectores de la población no son en realidad métodos de afiliación a una condición previamente asignada. En esto también tomaremos los aportes de Rancière (1996) sobre la distribución de las identidades, de los lugares y de las funciones en la sociedad.

En este marco de interpretación sobre la eficacia y existencia de la norma es que tomamos la Convención Internacional sobre los Derechos de las Personas con Discapacidad, aprobada por la Asamblea General de las Naciones Unidas, e incorporada a nuestro ordenamiento jurídico en mayo de 2008, a través de la Ley Nacional 26.378.

La convención mencionada plantea un cambio de paradigma en lo que atañe a la consideración de los derechos de las personas con discapacidad, quienes dejan de ser vistas como "objeto de políticas" para pasar a ser consideradas "sujetos de derecho". El cambio de paradigma mencionado se plasma profundamente en la materia capacidad jurídica, a través del 
artículo 12 de la mencionada convención, que remplaza el modelo de "sustitución en la toma de decisiones" por un modelo de "apoyo en la toma de decisiones". Este cambio conceptual y legal tiene importantes repercusiones prácticas en la intervención social del trabajador social.

La convención no crea nuevos derechos, sino que establece las garantías para que las personas con discapacidad puedan gozarlos y ejercerlos en igualdad de condiciones que las demás personas. A dichos fines, podría decirse que las dos columnas vertebrales que impregnan este tratado son los principios de igualdad y autonomía. Ambos principios aparecen reconocidos como principios, valores y derechos específicos, y se encuentran plasmados de manera muy especial en el artículo 12 sobre capacidad jurídica.

El mencionado artículo 12 no solo reconoce que las personas con discapacidad gozan de capacidad jurídica en igualdad de condiciones que las demás personas, sino que establece que los Estados deben garantizar ciertas medidas de apoyo a quienes lo requieran, para el ejercicio de dicha capacidad jurídica. Estas medidas de apoyo estarán sujetas a unas salvaguardas adecuadas y efectivas, de conformidad con el derecho internacional de los derechos humanos.

Si bien hasta la fecha se han adelantado algunos estudios relativos a las implicaciones de este cambio de paradigma desde el marco conceptual y jurídico en otros países, no existen investigaciones en nuestro país, o por lo menos no tienen la suficiente visibilización, que aborden desde un trabajo de campo las implicaciones derivadas en la intervención social concreta. Por ello, si bien el análisis de la convención se realiza en los niveles denominados legal, reglamentario y práctico, nuestro estudio se concentrará en este último nivel.

Si analizamos muy esquemáticamente el proceso legal de interdicción de una persona con discapacidad mental que se encuentra vigente en nuestro país, podemos identificar claramente dos pilares. El primero es la deshumanización del sujeto, que, sobre la base de una etiqueta médica, es considerado un ser incapaz de tomar decisiones. El segundo, y como consecuencia de lo anterior, es la cosificación del sujeto, quien se convierte en objeto al perder el absoluto control de su vida por la sustitución de su 
toma de decisiones, que queda en manos de otra persona-su representante-, quien a partir de entonces debe decidir sobre cualquier aspecto del sujeto sustituido, sin necesidad de consultarle o participarle de dichas decisiones. De este modo, aspectos fundamentales de las relaciones sociales intersubjetivas, como el amor, el cariño, la confianza o la amistad, pasan a constituir aspectos irrelevantes al momento de considerar la dinámica entre el sujeto interdicto y su tutor.

El cambio de paradigma del artículo 12 arremete frontalmente contra el citado esquema legal vigente, exigiendo el establecimiento de un nuevo esquema por el cual la persona no puede ser privada del goce y ejercicio de sus derechos sobre la base de su discapacidad mental ni intelectual, e instituyendo para su protección un sistema de intervención/red social (no únicamente individual) que le permita acceder a los apoyos necesarios para ejercer la toma de decisiones. Este sistema de apoyos requiere claramente de un marco de intervención social complejo y donde los aludidos aspectos de la relaciones intersubjetivas, como la relación de confianza y la promoción de la autonomía, cobran un protagonismo fundamental.

Precisamente, la intervención social, en palabras de Ruiz Ballesteros (2005a: 215), es "un campo de conflicto, de lucha de intereses, de modelos de sociedad y usos de los recursos disponibles; en definitiva -aplicando las ideas de Laclau (1998) - un contexto de expresión hegemónico en el que se da contenido identificador a la incompletud de la sociedad: un ámbito político en el que emerge el poder". Sin embargo, y como fenómeno producido, la debemos comprender sin tender a su naturalización, aunque sea "un fenómeno tan excepcional como cotidiano. Tan presente que apenas se nombra, tan cercano que no se diferencia, tan central que apenas se vislumbra" (Laclau, 2008: 79), pues, por más que no lo advirtamos, es un "dispositivo que se entromete en un espacio" (Carballeda, 2005: 91-92); "es una forma de actuar que se asienta en una forma de conocer y en una posición social subsecuente, que la habilita" (Ruiz Ballesteros, 2005b: 13).

La inteligibilidad de este escenario se configura (y se la "razona") como un "fenómeno central y estratégico para la organización social", y se la enmarca en una enmarañada y compleja malla de relaciones de poder entre todas las personas, instituciones y colectivos que entablen relación en torno 
a ella, constituyéndose en "un hecho multidimensional en el que entran en juego discursos, referentes organizacionales, profesionales, metodologías de intervención, instituciones, relaciones de poder" (Ruiz Ballesteros, 2005a: 215). De tal manera que la intervención social se conforma como "un proceso de transformación que sólo puede ser entendido plenamente si se analiza -al menos-desde tres dimensiones simultáneamente: la cultural, como gran referente desde el que se organiza la vida social; los discursos como modelos posibles de sociedad y de relación de las culturas, y el poder, como forma en que se articulan culturas y discursos a través de la intervención social" (Ruiz Ballesteros, 2005b: 14).

El trabajo social utiliza la intervención social porque es donde

Se articula lo macrosocial con lo micro en la singularidad de los padecimientos; así, en la medida que tengamos en cuenta esa articulación, ella es posible como constructora de acontecimiento, fundamentalmente haciendo ver aquello que permanece oculto, articulando lo que la crisis fragmentó, recreando nuevas formas de encuentro, de interpretación, donde la voz principal surge de la palabra del otro. De aquel sobre el que ejercemos y compartimos nuestra práctica en forma cotidiana (Carballeda, 2004: 34).

Una práctica que entendemos como práctica política, ya que desde los orígenes de la intervención existe una construcción discursiva del "otro", ese "otro" al cual consideramos sujeto de nuestra intervención.

Lo que intentamos apuntar es que lo "social en términos de intervención remite, entonces, a la idea de conjuntos de dispositivos de asistencia y de seguros en función de mantener el orden y la cohesión de lo que denominamos sociedad" (Carballeda, 2005: 91). Pero también debemos tener presente que

La intervención nos recuerda que la palabra, la mirada y la escucha conforman hoy una parte clave del desarrollo de ésta. Así, la intervención en lo social, en la medida en que profundiza y da una dirección determinada al conocimiento que obtiene, tiene la oportunidad de transformarse en constructora de "acontecimientos", haciendo visible aquello que la agenda pública muchas veces no incorpora o registra. Instalando nuevos 
territorios que rompen la dicotomía de lo particular-universal, generando un desplazamiento de sentidos, que conlleva una desarticulación posible de órdenes previamente constituidos (Carballeda, 2004: 34).

Es por eso que planteamos, con Fernández Soto (2004:106), que

Se entiende que es necesario desde el campo profesional establecer, a partir de una reflexión crítica, estrategias profesionales adecuadas para responder a las problemáticas emergentes, visualizando los limites objetivos que se nos presentan como así también las posibilidades históricas de superación de una práctica restringida e inmediatista, reducida en el contexto del neoliberalismo a "administrar la crisis", "focalizar a los pobres", y "gestionar eficientemente recursos escasos"; para potenciar el fortalecimiento de una práctica de respeto y ampliación de las conquistas civilizatorias, basada en la lógica de la ciudadanía y los derechos sociales".

En el proyecto que nos alienta queremos analizar cómo, desde la intervención social, el trabajo social visibiliza ese trabajo que las personas con padecimiento mental realizan sobre las condiciones económicas y sociales en las cuales están inmersas, sobre la libertad que poseen y sobre la invalidación de la cual son objeto. Trabajo que se suma a la construcción de la sociedad en la que viven, restituyendo la capacidad jurídica, la autonomía y la ciudadanía.

\section{Desarrollo}

El propósito de nuestra investigación no es ambicionar como única medida viable (para la conquista de derechos sociales y civiles en la interdicción) la reforma del Código Civil solamente. Es, más bien, analizar la Convención Internacional de los Derechos de las Personas con Discapacidad como herramienta valiosa para la intervención social que realiza el trabajador social, desde la cual es posible llevar a cabo acciones liberadoras que reposicionan al sujeto no como objeto de protección, sino como sujeto pleno de derechos, devolviéndole tal condición en el desarrollo de su autonomía, capacidad jurídica y ejercicio de ciudadanía. 
A partir del análisis de la intervención social que realizamos en el campo de la salud mental, deducimos la necesidad de establecer tres proposiciones:

\section{a) Subvertir la forma en la cual se proponen los aspectos centrales de toda discusión sobre la profesión del trabajo social en un campo determinado}

La tarea de indagar sobre el tema o el campo a investigar se inicia usualmente con la descripción, la historia, las características y los objetivos que las ciencias sociales o médicas, como en este caso, plantean para ese campo o tema, para luego, posteriormente, definir el lugar que nuestra disciplina ocupa en ese tema o campo. Sin embargo, esta forma de realizar los planteamientos, en algunos casos muy rigurosa, termina por decir más sobre el tema desde las otras disciplinas, que sobre lo que el trabajo social hace en él, o puede hacer. Por eso nosotros decimos que primero debemos preguntarnos qué tiene el trabajo social para formar parte o explorar ese campo o tema, y qué características de su marco axiológico, su estructura teórica y su práctica concreta han hecho posible la participación del trabajo social en ese campo -y no al revés-. De esta manera, no nos ubicamos en el juego de la construcción del conocimiento en un lugar ya predefinido por otras ciencias, en este caso la psiquiatría o la psicología, sino que nos presentamos como otro factor más que promueve la dinámica del conocimiento en el tema planteado, a partir del interjuego de las fuerzas que componen el campo (Bordieu, 2000).

Nuestra participación en el campo de la salud mental no es por una generosa invitación de otras disciplinas, sino por la necesidad que el campo tiene de integrar lo que el trabajo social "sabe hacer", y de esta manera poder abarcar la complejidad de los fenómenos que ocurren en él. Queremos decir que el campo, en este caso el de la salud mental, se constituye como tal con la necesaria participación del trabajo social.

Esta última afirmación encuentra su corolario en la definición que tomamos para explicitar lo que entendemos por salud mental, y que es la dada por la Ley Nacional de Salud Mental (26.657) cuando en su artículo $3 .^{\circ}$ expresa: "En el marco de la presente ley se reconoce a la 
salud mental como un proceso determinado por componentes históricos, socioeconómicos, culturales, biológicos y psicológicos, cuya preservación y mejoramiento implica una dinámica de construcción social vinculada a la concreción de los derechos humanos y sociales de toda persona".

Es importante dilucidar este asunto, pues lleva a la confusión, muy generalizada por cierto, incluso dentro de grandes estratos de nuestra profesión, ${ }^{1}$ de creer que es natural que el trabajo social tenga una posición subalterna en los campos en los cuales participa, ya que siempre es otra la profesión que en forma unitaria establece el campo, en este caso la psiquiatría. Pero este discurso, en realidad, no es en sí mismo ni verdadero ni falso, excepto que se lo relacione con efectos prácticos de poder. Entonces es allí cuando a un enunciado se le otorga "el estatuto de verdad" y pasa a formar parte del régimen de verdad imperante.

La jerarquización científica no es un discurso neutro sobre los saberes; la adjudicación de campos de saber y de profesiones que forman ese campo de saber es una operación estratégica que realiza desde el poder "la formación de ciertos y determinados dominios de saber a partir de relaciones de fuerza y relaciones políticas en la sociedad" (Foucault, 2003: 31).

Este proceso de diferenciación entre ciencias específicas para determinados campos comienza en el siglo XIX, con el estudio del hombre como objeto. Es decir, además de la sensibilidad y la necesidad de comprender los fenómenos sociales por parte de los grandes humanistas, y del descubrimiento de la manera como las condiciones económicas de la existencia encuentra su reflejo en la conciencia de los sujetos, lo que encontramos es toda una nueva tecnología sobre la vida del hombre y la sociedad que se deposita sobre los individuos, las instituciones y los cuerpos. Lo que encontramos son prácticas sociales y discursivas que tienen que ver con los comportamientos del hombre en su esfera productiva y de consumo, así como en sus redes vitales.

\footnotetext{
${ }^{1}$ Sobre el tema del colonialismo dentro de la profesión, ver "El discurso sobre el poder en la intervención profesional: otro caso de la colonización del trabajo social por el régimen de verdad de las ciencias sociales" de Rubens R. Méndez, en www.diporets.org.
} 
Lo que encontramos es la invención ${ }^{2}$ de diferentes prácticas que determinan comportamientos que promueven nuevas formas de asociatividad, de dar la lucha política, de representarse el trabajo en la vida personal y en la familiar, de llevar adelante los vínculos, de entender la democracia y de pensar las instituciones. La invención de diferentes saberes provenientes de estas prácticas sociales y discursivas sobre el sujeto, su individualidad, y sobre la manera como se constituye en persona, se transforma en normal u anormal; así como la razón de su soberanía y de la manera como llega a su libertad. Lo que encontramos, en fin, es la invención de un nuevo orden que Foucault denomina "la episteme" y que se compone de todas las prácticas discursivas y no discursivas que forman las condiciones de posibilidad para que emerja un acontecimiento nuevo; en el caso que nos ocupa, las denominadas ciencias modernas o ciencias humanas.

La psicología, la psiquiatría, la pedagogía, el derecho, el trabajo social, la antropología, la sociología, la economía y la enfermería muestran cómo se forman nuevas tecnologías sobre los hombres y sus cuerpos, que necesitan de esas ciencias del hombre para que los estudien y perfeccionen, y cómo las instituciones y los sistemas de regulación a su vez forman y sostienen a estas nuevas ciencias humanas. Así lo plantea Esther Díaz (1995: 71):

Ni la filosofía, ni la política, ni moral alguna, ni tampoco las ciencias empíricas habían tematizado, antes de entonces, algo así como el hombre, en tanto ser vivo que trabaja y habla, no ya "ser racional", sino ser determinado desde las cosas, desde las positividades: la vida, el trabajo, el habla. Al finalizar el siglo XVIII, el hombre se coloca al lado de los objetos científicos: se convierte en objeto del pensar y del saber.

Decir que todas estas ciencias provienen del mismo suelo de condiciones de posibilidad en determinado momento agrieta la noción de orígenes individuales, aunque se reconoce el hecho de distintos desarrollos ulteriores. O sea, que da por tierra a quienes quieren justificar el crecimiento de una u otra disciplina a partir de su origen. Pero además

\footnotetext{
${ }^{2}$ Invención en oposición a "origen", como lo plantea Nietzsche en varias de sus obras y que resume claramente Foucault en su conferencia "Nietzsche, la genealogía, la historia" (1980). Se trata de mostrar cómo el origen divino y prístino de las cosas es en realidad una invención "humana demasiado humana".
} 
establece una ruptura con la noción de "objeto" comúnmente aceptada, ya que no es que haya un "objeto" a priori que espera ser develado y que con su descubrimiento se constituye la disciplina. Lo que hay es un espacio en el que los objetos se forman y es este espacio el que les da su unidad. "El objeto no "espera" al discurso. La red de emergencia de los objetos aparece cuando el análisis remite a instituciones, procesos económico-sociales, formas de comportamiento. Sistemas de normas y técnicas" (Abraham, 1989: 83).

Es decir, desde mediados del siglo XIX y principios del XX nos encontramos con un nuevo espacio donde se dan múltiples relaciones y formas de vivir la vida concreta de las personas, donde se experimentan distintas formas de llevar adelante la cotidianidad y donde emergen distintos saberes y estrategias para esa vida. Y allí, en ese espacio, se construyen los objetos de las ciencias sociales, ciencias humanas o ciencias modernas.

Lo que muestra la realidad es que no existe unicidad en el objeto, sino que la unidad que se observa es la unidad del lugar donde se forma el objeto. Es por ello que los procesos económico-sociales (la sociedad del trabajo, la lucha contra los no proletarios), las reglamentaciones institucionales (necesidad del encierro del otro, del diferente), las resoluciones judiciales (penalización de la pobreza y las familias llamadas disfuncionales), las disposiciones administrativas (control de la población) y los estudios sobre el comportamiento (gnoseología sobre la enfermedad mental, DSM) constituyen la red de emergencia que da como resultado el objeto -locura-. Es decir, el objeto del campo no es producto del desenvolvimiento de una sola disciplina, sino que aparece en la emergencia de múltiples disciplinas, una de las cuales es el trabajo social.

\section{b) Ser conscientes de que la utilización del conocimiento científico imprime responsabilidad política a la prescripción científica en cualquier disciplina, pero que en trabajo social esta característica es parte de su especificidad}

Lo que queremos decir es que es común que algunos autores del servicio social expresen que nuestra disciplina construye su material crítico utilizando ideas y formulaciones ya establecidas por otros, ubicándonos de 
esta manera en un escalón por debajo de los sistemas de conocimiento que crean teorías. Si bien esto puede ser cierto, como en otras disciplinas, lo que en parte se ignora es que la forma como el trabajo social utiliza esas teorías es contraponiendo y modelando dichos pensamientos con las circunstancias históricamente determinadas y existencialmente posicionadas, creando nuevas perspectivas para esas teorías (perspectivas que tal vez no fueron vislumbradas en el momento de su creación). A nosotros no nos parece poco que nuestra profesión tome como su interés primordial no solo el problema de las condiciones y posibilidades del conocimiento, sino también el problema de las consecuencias efectivas y potenciales de la utilización de los conocimientos (Dewey, 1964).

Esta capacidad del trabajo social, que para nosotros es parte de su especificidad, hace que en muchas oportunidades su intervención profesional no se conforme a los estándares del cientificismo, y tal vez por ello se advierta a la disciplina como una práctica que no puede aportar nada nuevo al sistema científico en general. Este prejuicio sobre la capacidad de la profesión para construir conocimiento no solo proviene de contextos ajenos al trabajo social, sino que también se debate dentro de la profesión. Incluso por ello existen corrientes que postulan la aceptación por parte de la disciplina de modelos importados de investigación o de intervención profesional que ya encierran las cosmovisiones necesarias para leer la realidad social a investigar, dando lugar así a las modas dentro de la profesión.

Sobre esta discusión, ya Varsavsky (1969: 17) nos prevenía:

Cientificista es el investigador que se ha adaptado a este mercado científico, que renuncia a preocuparse por el significado social de su actividad, desvinculándola de los problemas políticos, y se entrega de lleno a su "carrera", aceptando para ella las normas y los valores de los grandes centros internacionales, concentrados en un escalafón. El cientificismo es un factor importante en el proceso de desnacionalización que estamos sufriendo; refuerza nuestra dependencia cultural y económica, y nos hace satélites de ciertos polos mundiales de desarrollo.

En este esquema propuesto por el autor, está claro que siempre le va a costar al trabajo social formar parte del sistema científico establecido. 
En nuestra disciplina, lo político es constitutivo del proceso de intervención, desde el momento en que cualquier planteamiento de intervención profesional tiene en cuenta al sujeto social, específicamente en tanto sujeto que puede realizar las acciones políticas por él mismo identificadas como necesarias en el medio social que lo rodea y que se le presenta como resistente y, en algunos casos, como determinante. Pero además, el espacio de nuestras investigaciones y nuestra intervención recupera al sujeto social dentro de la trama de la micropolítica en la que participa.

Para nosotros existe un lugar donde se despliega una actitud constante de recursividad y dialogicidad entre los sujetos mismos, los otros y el medio social en el que estamos conviviendo, es decir "lo cotidiano". Y es en ese lugar donde el sujeto asume la cuestión política y el desafío del cambio social. Así lo ejemplifica Cornelius Castoriadis (2006: 43):

La gente cree: "lo que a mí me preocupa no tiene mucha importancia, son pequeñas imbecilidades personales; yo no puedo hablar de los asuntos de la sociedad porque no conozco nada de ellos". Tenemos que destruir los efectos de este trabajo, invertir los signos de valor, difundir la idea evidente de que todos los discursos que de manera cotidiana inundan los diarios, la radio, la televisión tienen una importancia casi nula y que las preocupaciones de la gente son el único asunto importante desde el punto de vista social.

La intervención profesional sobre distintos temas de la realidad social desde la práctica del trabajo social permite observar resistencias al sometimiento contra las diversas formas de subjetividad, sumisión y normatización de la vida cotidiana, en oposición a los conocidos discursos de resistencia a la dominación y a la exclusión, que en general se utilizan en formas totalizadoras y por lo tanto ineficaces. La posibilidad de intervenir sobre los aspectos de la construcción del sentido en la cotidianidad nos muestra las resistencias, dentro de las relaciones sociales, a las formas normalizadas de establecer esas relaciones sociales, y también resistencias a la forma de establecer los vínculos que el régimen de verdad sanciona como "apropiados". Estas situaciones son las que nos llevan a pensar que 
las personas o grupos denominados "asistidos" (término que en política social es sinónimo de incapacidad funcional, pasividad o desventaja) son en realidad sujetos sociales que activan procesos de resistencia al discurso que proviene de las instituciones normalizadoras. No por el hecho de oponerse, sino por el hecho de sostener un discurso propio.

Sostenemos que se debe reconocer que los cambios de la sociedad y de los grupos sociales son también, y sobre todo, los cambios y adaptaciones logrados por las distintas formas de resistencia que hacen los sujetos cotidianamente.

No hay un sujeto que pasivamente sea constituido dentro de las prácticas sociales, los discursos del saber y las relaciones de poder; existe también ese mismo sujeto resistiendo a esas prácticas sociales, a ese régimen de verdad y a esas relaciones de poder. Y esto no debe ser ignorado o considerado como secundario, porque aquellos sistemas científicos de interpretación sobre la cuestión social que minimizaron este lugar son ahora otras tantas utopías sobre el cambio.

Por eso nosotros decimos que enfocar la mirada sobre los intereses de los sujetos en sus asuntos comunes no es darle importancia solo a lo singular, sino identificar el lugar político donde se establece la lucha y la discusión por lo común. Entendiendo a esta lucha como el combate por el sentido y las interpretaciones de lo que posteriormente se instalará como lo "común-real". Algo tan preciado dentro del campo de la salud mental.

\section{c) Comprender la utilidad de definir las estrategias a realizar en el campo de la salud mental}

La particularidad que Bordieu nos presenta en la definición de campo es aquella en la que el autor establece el campo como el espacio intermedio entre dos opciones contrapuestas. Una de ellas cree que la interpretación y la comprensión de las producciones culturales, en este caso la ciencia, y en particular el subcampo de la salud mental, se deben hacer solo y específicamente desde los materiales que esas mismas producciones culturales generan. O sea, se puede interpretar lo que pasa en la salud mental sólo desde los escritos o productos que ella realiza. 
Otra visión establece que se puede llegar a comprender esas producciones culturales (ciencia, salud mental) sólo poniéndolas en relación directa con el medio económico o el medio social. Aclaremos que es el mismo Bordieu quien señala que esta posición suele ser común en el marxismo.

Algunos autores del trabajo social son partidarios de la hipótesis del contexto social como sobredeterminante en la constitución del campo. Esta hipótesis lleva a que en nuestra práctica diaria no se realicen acciones ni se diseñen formas de intervención, por la parálisis que el reconocimiento de esta hipótesis significa. Pero este defecto o error, usualmente propuesto por cierto marxismo académico, queda evidenciado cuando observamos que los campos pueden adquirir distintos niveles de autonomía por sobre la determinación del contexto social.

Un ejemplo común de estas interpretaciones polares sobre las prácticas incluidas en un campo son las que identifican las acciones del trabajador social en el campo como resultantes de la coacción que todo el campo ejerce sobre él, sin dejar la posibilidad de investigar las acciones que el servicio social efectivamente realiza y que no necesariamente responden automáticamente a lo que "se presume que hace".

Esta forma apriorística de ver las cosas no hace más que una lectura homogénea de todas las disciplinas dentro del campo, y por ello es ineficaz, o por lo menos incompleta, para definir las distintas estrategias que se desenvuelven en dicho campo. Por ejemplo, es un reduccionismo manifestar que aquellos agentes que conforman el campo de la salud mental son "serviles" a las presiones económico-políticas del sistema en general y de la salud mental en particular porque, si ello fuera así, el movimiento antipsiquiátrico no hubiera podido existir.

Lo importante es, en uno u otro caso, observar el posicionamiento del trabajo social dentro de esas estrategias y dilucidar las posiciones que el trabajo social ocupa en el campo de la salud mental en relación con las posiciones de las otras profesiones, las coacciones a las que es sometido, las leyes del campo, las jugadas que el servicio social puede realizar dentro de él y la estructura de las relaciones objetivas entre los agentes de dicho campo. La discusión sobre el diagnóstico es uno de estos ejemplos sobre 
el lugar estratégico del trabajo social en el campo y las fuerzas que se desenvuelven en él.

\section{La cuestión}

Existe una característica básica y específica que presenta el trabajo social en la batalla para modificar las fuerzas dentro del campo y para redefinir el conjunto de objetos y de cuestiones que importen a los investigadores y operadores de dicho campo. Esta diferencia tiene que ver con el hecho de que en el cuerpo teórico del servicio social, y desde sus orígenes, está planteado que esta es una profesión que llega al hombre desde sus relaciones sociales, desde su lugar en el medio social y en la sociedad en general. Para nuestra profesión, en este campo, no es sólo importante evaluar las condiciones psicológicas de la aparición del padecimiento mental en un sujeto dado, sino, y de manera más específica, "las condiciones sociales e históricas que fundamentan los conflictos psicológicos en las contradicciones reales del medio" (Foucault, 961: 87).

La inteligencia, la reflexión, la conciencia de sí, el manejo de las emociones, los atributos del ser persona no vienen dados, son tan sólo posibilidades o, como diría Merleau-Ponty, horizontes posibles.

En el desarrollo social del ser persona se van construyendo esas estructuras o, si se prefiere, se van alcanzando esos niveles, que van conteniendo el uno al otro. Pero si ese desarrollo social es deficitario en brindar los elementos básicos para elaborar nuevas significaciones vitales, se produce el defecto, la falla, que se presenta como un resultado individual, olvidando el carácter constitutivo de lo social en la génesis del proceso.

Indudablemente, este tipo de planteamiento coloca a las posibilidades, obstáculos y facilidades que ofrece la sociedad a sus miembros en un lugar de importancia para comprender la génesis de algunos comportamientos que aparecen reservados sólo a la sanción individual.

Es esta característica de privilegiar las relaciones sociales en la constitución del ser persona (Mead, 1993), que, por otra parte, funda lo "social" para nuestra profesión, la que da "especificidad a nuestro capital científico" en el campo, especialmente si para el campo dicho capital 
científico no es el dominante o el que ocupa las posiciones de privilegio. Es esta especificidad dentro del campo la que resiste a los embates de las estrategias de conservación de aquellas disciplinas que ocupan las posiciones más altas en el campo de la salud mental -psiquiatras y psicólogos-. ${ }^{3}$

Aun en las personas con padecimiento psíquico hay un esfuerzo del hombre por recobrarse, por comprenderse (Merleau-Ponty, 1977), y es en este contexto existencial del hombre para consigo mismo y con la sociedad donde el trabajo social tiene algo que aportar a este esfuerzo. ¿Desde dónde? Desde el análisis y evaluación que hace la persona con padecimiento psíquico acerca de la experiencia concreta de su cotidianidad.

Sabemos que existe un orden biológico, un orden psíquico y un orden espiritual, pero esto no significa que estos órdenes estén separados y sean independientes entre sí, sino que están integrados en lo que "verdaderamente es un cuerpo humano [y que] estas distinciones son entonces las de diferentes regiones de la experiencia" (Merleau-Ponty, 1953).

En el cuerpo teórico del trabajo social hay una hipótesis que plantea que la posibilidad de establecer relaciones satisfactorias con el medio, por parte de las personas, puede significar la resolución de cuestiones internas. Es lo que Merleau-Ponty nos quiere decir cuando afirma: "las relaciones satisfactorias que podemos establecer en nuestro denominado mundo de las cosas o el mundo objetivo; nos conducen también, a establecer relaciones satisfactorias o porqué no, cambios, en el denominado mundo interno".

En nuestra práctica cotidiana, los trabajadores sociales observamos innumerables ejemplos de personas con padecimiento mental a las cuales se les reservaba para su futuro una vida de internación como única respuesta posible a las características de su diagnóstico. En la mayoría de los casos ya eran personas que estaban padeciendo una larga internación. También sabemos sobre reuniones del equipo de profesionales donde la mínima propuesta de comenzar con un proceso de reinserción social es vista con

\footnotetext{
${ }^{3}$ Debemos mencionar que existen corrientes dentro de la psiquiatría y la psicología que le dan la importancia necesaria a la organización social en la construcción del hecho psíquico. Un ejemplo de ello es Wilhelm Reich (2001: 4) cuando dice: "cada organización social produce las estructuras de carácter que necesita para existir.[por ello] la psicología científica natural y la caracterología tienen una tarea claramente definida: trazar los caminos y los mecanismos por los cuales la existencia social de los hombres se transforma en su estructura psíquica y, consecuentemente, en ideología".
} 
hilaridad o con cierta indulgencia por parte del poder psiquiátrico, el cual, la mayoría de las veces, accede, no por convencimiento en el proceso, sino por sacarse un problema de encima; y también hemos visto discusiones sobre la externación que se debe hacer "por criterio médico", sin evaluar si la persona cuenta con un medio social receptivo.

El trabajo social no tiene herramientas del discurso psiquiátrico para discutir los niveles de desorganización en el cual una persona puede caer, lo cual es lógico porque nuestro discurso no es el psiquiátrico. Pero sí tiene herramientas metodológicas para establecer cómo es el desenvolvimiento social de una persona o el reconocimiento que ella tiene de su desenvolvimiento y que nos permite manifestar sus posibilidades y capacidades de estructurar una experiencia humana. Todo ello teniendo en cuenta claramente que la experiencia humana, si bien se asienta en el lenguaje, no es toda ella lenguaje. ${ }^{4}$

Es por ello que nosotros denominamos trabajo a la actividad que realiza sobre sí la persona con padecimiento mental y sobre su existencia, y que también incluye la construcción material de su entorno y la realización de sí. Todo ello por las acciones que puede llevar adelante en el mundo de la vida. Es decir, para el trabajo social no se puede aislar la experiencia del contexto más amplio donde esta acontece.

Para el trabajo social no se trata, porque no es su especificidad, de ubicar en un nicho de una taxonomía psiquiátrica a los síntomas o hechos que la persona con padecimiento mental presenta, sino de estimar y valuar los signos que la persona con padecimiento mental da como certezas y con los cuales compone su experiencia del mundo y en-el-mundo. Específicamente de aquellos signos que tienen que ver con el reconocimiento que la persona con padecimiento mental registra de los otros; del ser social que lo rodea.

El servicio social trabaja en esas regiones de la experiencia que muestran la adquisición, por parte de la persona, de ciertas prácticas sociales por sobre otras. Y donde se observan las prácticas que las personas hacen sobre

\footnotetext{
4 "Resulta necesario entonces revisar la posibilidad de operar apelando a maniobras que exceden el campo de la "institución" en la que el psicótico no se encuentra cómodo -la del lenguaje-. Puede ser útil propiciar -en algunos casos- que pueda acomodarse en otra institución. Y que en ésta, el analista favorezca el despliegue de anhelos que orienten cada movimiento transferencial. El trabajo debería dirigirse luego hacia la creación de lugares donde el sujeto inscriba, haga marcas, con su palabra y producción" (Mesquida, 1996: 147).
} 
sí, para establecer las relaciones con aquellas formas de subjetivación que se le imponen. Este vector de la intervención de nuestra profesión es la que precisamente significa una discusión en el diagnóstico.

Toda práctica científica considera al diagnóstico como elemento central de la definición de su objeto, y por lo tanto reservado sólo a la disciplina que lo realiza. De esta manera, se comprende la resistencia que las profesiones presentan al momento del diagnóstico para incluir otras disciplinas. A esto debemos sumar el hecho de que, en cualquier actividad científica grupal institucionalizada, el diagnóstico se funcionaliza como una base comunicacional entre sus miembros. En el caso del campo de la salud mental, existe el reconocimiento fáctico de la dificultad de separar lo que es clínico de lo que es social, y éste es el punto central donde se produce el conflicto de interpretaciones.

El trabajo social plantea que la realización del diagnóstico clínico en el momento de la internación o admisión de una persona con padecimiento mental, sin la concurrencia en ese mismo momento del diagnóstico social, produce una evaluación ficticia de las capacidades y los recursos de la persona con padecimiento psíquico, así como de su sistema familiar o social, para el tratamiento posterior. Incluso nuestra experiencia nos ha mostrado casos en los cuales, si se hubiera contado con la participación de un trabajador social al momento del diagnóstico inicial, se podría haber utilizado otra estrategia de intervención que no fuera la internación, ya que muchas veces se esconde, en la demanda de cuidado para que la persona no se dañe a sí misma o a terceros, el deseo de los familiares, o de quienes realizan dicho procedimiento, de instar coactivamente a que el presunto enfermo realice tratamiento médico. ${ }^{5}$

Esta afirmación nace de la consideración que el trabajo social le da a la "dimensión simbólica de la enfermedad", que es la forma como la persona percibe su padecimiento y como se relaciona esta percepción con los demás y su medio social, porque es esta forma la que va a determinar la manera como la persona pondrá en juego el "cuidado de sí”. Es decir, para

${ }^{5}$ Estamos hablando de muchas internaciones que se realizan con personas que han sido encontradas en la vía pública y sólo por ello son internadas. O de personas que son llevadas a los servicios de salud mental por cuestiones de aparente peligrosidad y que en realidad sólo encierran disputas familiares, que una de las partes las resuelve judicializándolas. 
nuestra disciplina, el momento del diagnóstico debe ser un momento en el cual se realicen las evaluaciones de las capacidades que la persona posee, aun por sobre el padecimiento que presenta. Porque hablar de síntomas sin conocer lo que la persona refiere sobre las capacidades que posee para desenvolverse satisfactoriamente con su medio, es separar lo clínico de lo social.

Esta necesidad de incluir el manejo que la persona hace de sus relaciones es una forma de restitución de la historicidad de la persona con padecimiento mental, frente al procedimiento de ahistoricidad que la institución sostiene y que forma parte del discurso de la misma.

La historicidad para el trabajo social significa poner a esa persona dentro de un sistema de pertenencia: social, familiar, cultural, laboral, institucional, escolar, de relaciones; desde donde el hombre es significado y a su vez resignifica su realidad circundante. De esta forma, el delirio, las voces, o el síntoma más destacado al momento del análisis o aquel que dio lugar a la supuesta necesidad de internación, adquiere una o varias significaciones más allá de la taxonomía psiquiátrica que se le imponga. Por ello esta práctica de primero aislar, reconocer y controlar el padecimiento mental, para luego conectar a la persona así diagnosticada con todo su sistema de relaciones, nos muestra claramente la separación que la psiquiatría hace de lo real en el padecimiento mental -atribuyéndole sólo entidad de real a los síntomas y no a la encarnadura que esos síntomas hacen en determinada persona.

Si se psiquiatriza lo real, se está des-realizando a la persona que porta el padecimiento mental. Se está imponiendo al hombre la lógica de reconocer que es sólo en su interior, en su corazón, donde existe el desorden y la contradicción, y se trata de desligar a la persona de sus condiciones de existencia y de las contradicciones que vive en el medio, su familia, sus compañeros, su trabajo o en el hecho de no tener a nadie. De esta manera, se termina hablando de un hombre abstracto, y lo que es peor, se diseñan estrategias terapéuticas que caen por sí solas en lo abstracto. El trabajo social propone al respecto que no se puede separar la manifestación del padecimiento mental de las condiciones de su aparición; ni a la persona que lo padece de sus condiciones de existencia. Esto es sumamente importante, 
ya que de esta manera nuestra profesión se opone a la creación de un objeto de estudio, a partir de separar lo que aparece como una forma de "anormal en estado puro" de los datos que nos informen sobre el estado de alienación social e histórica previo a la enfermedad.

Las contradicciones sociales que la persona experimenta, los conflictos reales que vive y a los cuales no puede oponer una solución satisfactoria, conforman la realidad del padecimiento mental. Y si debemos basarnos en el padecimiento mismo para superarlo, ignorar estos vectores significa "la formulación incompleta del diagnóstico y la proposición ineficaz de algún tipo de tratamiento". Este discurso del trabajo social crea tensión al interior del campo y establece una dialéctica abierta entre los posicionamientos de las demás disciplinas, que es positiva para la formulación de las intervenciones.

Para nosotros, los factores denominados psicosociales a tener en cuenta en el diagnóstico son, en estos casos, la identificación del sistema de ayuda mutua en el cual la persona con padecimiento mental se encuentra y que forma su sistema de sostén, la forma como vivencia su ser-con-losotros y la manera como ejerce el control sobre su cotidianidad. Se trata de evaluar la inteligibilidad que el sujeto tiene sobre la acción que él mismo desenvuelve en su medio social y cómo observa que esa acción modifica su medio o produce reacciones del medio. De esta manera podremos evaluar las posibilidades y oportunidades que tiene el sujeto, aun con su padecimiento mental, de establecer un juicio sobre la situación actual, que contenga una expectativa de resolución posible.

En resumen: relanzar a la discusión sobre el diagnóstico en salud mental los contenidos que tienen que ver con el desenvolvimiento de la persona en su sistema de sostén social y familiar, y la experiencia que esta persona tiene sobre su ser-con-los-otros, es el pensamiento de la profesión en el campo, y es el lugar que estructura las relaciones objetivas y las luchas entre los agentes del campo de la salud mental. 


\section{Conclusión}

Del trabajo de investigación realizado se puede inferir que, desde la promulgación de la Ley Nacional 26.378 en el año 2008, que incorpora a nuestro ordenamiento jurídico la Convención Internacional sobre los Derechos de las Personas con Discapacidad, aprobada por la Asamblea General de las Naciones Unidas, en el campo de la salud mental se están produciendo movimientos y resignificaciones en las instituciones que operan en el campo y en los cuerpos profesionales que también lo conforman. Estas nuevas disposiciones están en este momento en plena disputa con otras normas preexistentes de nuestra legislación que la contradicen y que por el momento ostentan la "fuerza de ley", creando de esta manera un proceso de hibridación de las prácticas y los discursos. Incluso la nueva Ley Nacional de Salud Mental N. ${ }^{\circ}$ 26.657, sancionada en el año 2010 (que no es motivo de esta investigación) también está generando estas cuestiones en la práctica.

A partir de la formulación de nuestros objetivos de investigación, nos planteamos iniciar una búsqueda de hallazgos sobre aquello que genera la intervención social del trabajador social en el campo de la salud mental a partir de prácticas concretas que, si bien, como hemos mencionado, aparecen "encabalgadas entre dos paradigmas (rehabilitador y social)", en ellas el trabajador social muestra la posibilidad de generar espacios en el ejercicio efectivo y real de derechos sociales y civiles en el campo de la salud mental, con acciones puntuales micropolíticas y prácticas liberadoras cotidianas, constantes y sociales. Esto desde el reconocimiento explícito de la titularidad que le confiere el derecho a tener derechos a quienes se constituyeron como sujetos de intervención.

En este momento estamos trabajando sobre los indicadores de la práctica del trabajador social que nos permitan identificar cuáles son las acciones que realiza y que se direccionan hacia la restitución de la autonomía, como las acciones dirigidas hacia la restitución de la capacidad jurídica y las que se direccionan hacia la restitución de la ciudadanía. La práctica profesional y discursiva sobre el proceso de la elaboración del diagnóstico es el elemento que cataliza la reunión entre la cuestión macrosocial y la microsocial. 


\section{Referencias bibliográficas}

Abraham, Tomás (1989). Los senderos de Foucault. Buenos Aires: Nueva Visión. Agamben, Giorgio (2007). Estado de excepción. Buenos Aires: Adriana Hidalgo. Arendt, Hannah (1998). La condición humana. Barcelona: Paidós.

Baudrillard, Jean (1984). El desplazamiento de lo político, en: Utopía, Quilmes, Año 1, N. ${ }^{\circ}$ 2, pp. 31-34.

Baumann, U. y Pérez, M. (1994). Manual de psicología clínica. Barcelona: Herder. Berger y Luckman (1989). La construcción social de la realidad. Buenos Aires: Amorrortu.

Bourdieu, Pierre (1999). Intelectuales, politica y poder. Buenos Aires: Eudeba. (2000). Los usos sociales de la ciencia. Buenos Aires: Nueva Visión.

Butler, Judith (2006). Vida precaria. El poder del duelo y la violencia. Buenos Aires: Paidós.

Butler, J. y Spivak, Gayatri (2009). ¿Quién le canta al Estado-Nación? Lenguaje, política, pertenencia. Buenos Aires: Paidós.

Carballeda, Alfredo (2004). La Intervención en lo Social y las nuevas formas de Padecimiento en Revista Escenarios, $\mathrm{N}^{\circ} 8$, Año 4. Buenos Aires. Espacio (2005). La intervención en lo social. Exclusión e integración en los nuevos escenarios sociales. Buenos Aires: Paidós.

(2007). Escuchar las prácticas. La supervisión como proceso de análisis de la intervención en lo social. Buenos Aires: Espacio.

Castoriadis, Cornelius (2006). Una sociedad a la deriva. Buenos Aires: Katz.

Código Civil de la República Argentina (2008). Buenos Aires: Edición Universitaria. Errepar S.A.

Constitución Nacional Argentina [Versión digital]. Disponible en: http://www. biblioteca.jus.gov.ar/constituciones-argentina.html. Consultado: 16 de febrero de 2010.

Convención de los Derechos de las Personas con Discapacidad. Ley 26.378, año 2008 [Versión digital]. Disponible en: http://www.senado.gov.ar/web/ proyectos/numley.php . Consulta: 20 de mayo de 2010.

De Souza Miyano, María (2003). Investigación social: teoría, método y creatividad. Buenos Aires: Lugar.

Dewey, John (1964). Naturaleza humana y conducta. México: Fondo de Cultura Económica.

Díaz, Esther (1997). Metodología de las ciencias sociales. Buenos Aires: Biblos.

Eroles, Carlos (1997). Los derechos humanos, compromiso ético del trabajador social. Buenos Aires: Espacio.

Eroles, Carlos y Carlos Ferreres (2002). La discapacidad, una cuestión de derechos humanos. Buenos Aires: Espacio. 
Extcheverria Mauleon, Xabier (2008). La condición de ciudadanía de las personas con discapacidad intelectual. Buenos Aires: Bilbao. Universidad de Deusto.

Famá, Victoria; Herrera Marisa y Pagano Luz (2008). Salud mental en el derecho de familia. Buenos Aires. Hammurabi.

Fernández Soto, Ma. Silvia (2004) Implicancias de la Cuestión Social en la Intervención Profesional en Revista Escenarios, No 8, Año 4. Buenos Aires. Espacio

Foucault, Michael (1961). Enfermedad mental y personalidad. Buenos Aires: Paidós.

(1980). Microfisica del poder. Madrid: La Piqueta. (1981). Un diálogo sobre el poder. Madrid: Alianza. (2003). La verdad y las formas jurídicas. Barcelona: Gedisa.

Galende, Emiliano y Kraut, Alfredo (2006). El sufrimiento mental: El poder, la ley $y$ los derechos. Buenos Aires: Lugar.

Gargarella, Roberto (2005). El derecho a resistir el derecho. Buenos Aires: Miño y Dávila.

Guía básica para comprender y utilizar la Convención sobre los Derechos de las Personas con Discapacidad. "Por un mundo accesible e inclusivo". Handicap Internacional. I.I.D.I.

Laclau, Ernesto (2008). Debates y combates. Buenos Aires: Fondo de Cultura Económica.

Ley Nacional de Empleo No 24.013 [Versión digital]. Disponible en: http:// www. snr.gov.ar. Consulta: 15 de mayo de 2010.

Ley $\mathrm{N}^{\circ} 25.785$ Personas con discapacidad-acceso a programas sociales [Versión digital]. Disponible en: http:// www.snr.gov.ar. Consulta: 6 de junio de 2010.

Ley $\mathrm{N}^{\mathrm{o}} 25.644$ Discapacitados-colectivo terrestre [Versión digital]. Disponible en: http:// www.snr.gov.ar. Consulta: 15 de mayo de 2010.

Ley $\mathrm{N}^{\mathrm{o}} 25.643$ Turismo accesible y personas discapacitadas [Versión digital]. Disponible en: http:// www.snr.gov.ar. Consulta: 15 de mayo 2010.

Ley $\mathrm{N}^{\mathrm{o}} 25.280$ Convenciones - discriminación de personas con discapacidad [Versión digital]. Disponible en: http:// www.snr.gov.ar. Consulta: 15 de mayo 2010.

Ley Nacional No 24.901 Sistema de prestaciones básicas de atención integral de las personas con discapacidad [Versión digital]. Disponible en: http:// www. snr.gov.ar. Consulta: 6 de junio de 2010.

Ley $\mathrm{N}^{\circ} 23.660$ Obras sociales- nuevo régimen [Versión digital]. Disponible en: http://www.snr.gov.ar. Consulta: 6 de junio de 2010.

Ley Nacional de Subsidios No 10.315 [Versión digital]. Disponible en: http:// www.snr.gov.ar. Consulta: 11 de abril de 2010. 
Mead, G. H. (1993), Espíritu, Persona y Sociedad. Desde el punto de vista del conductismo social, México, Paidós.

Méndez, Rubens (2006). Trabajo social en el campo de la salud mental. Mar del Plata. Facultad de Ciencias de la Salud y Servicio Social. (2009). El discurso sobre el poder en la intervención profesional: otro caso de la colonización del trabajo social por el régimen de verdad de las ciencias sociales, en: Revista Acciones e Investigaciones Sociales, Zaragoza. Facultad de Ciencias Sociales y del Trabajo. Universidad de Zaragoza. N. ${ }^{\circ} 27$, julio de 2009, pp. 111-129.

Merleau-Ponty, Maurice (1985). Fenomenología de la percepción. Barcelona: Planeta.

(1977). Sentido y sinsentido. Barcelona: Península.

(1953). La estructura del comportamiento. Buenos Aires: Hachette.

Mesquida, María del Carmen (1996). El analista y las psicosis. Interrogando un lugar, en: Psicoanálisis y el hospital. Buenos Aires, Ed. del Seminario. Año 5, N. ${ }^{\circ} 9$ pp. $145-148$.

Palacios, Agustina (2008). El modelo social de discapacidad: origenes, caracterización y plasmación en la Convención Internacional de las Personas con Discapacidad. Madrid: CINCA.

Rancière, Jacques (2007). El desacuerdo. Política y filosofía. Buenos Aires: Nueva Visión.

Reich, Wilhelm (2001). Análise do Caráter. Sao Paulo: Martins Fontes.

Richmond, Mary (1965). Social Diagnosis. New York: The Free Press.

(1962). Caso social individual. Buenos Aires: Escuela Nacional de Educación Pública.

Rolland, John (2000). Familias, enfermedad y discapacidad. Barcelona: Gedisa. Ruiz Ballesteros, Esteban (2005a). Intervención Social, Investigación Participativa y Complejidad en "Con Edgar Morin por un Pensamiento Complejo: Implicaciones Interdisciplinarias. Madrid: Akal.

Ruiz Ballesteros, Esteban (2005b). Intervención social: cultura, discursos y poder. Aportaciones desde la antropología. Madrid: Talasa.

San Giacomo Parodi, Osvaldo (2001). Trabajo social y conocimiento objetivo. Mar del Plata: UNMDP. Fundación Paideia.

Taylor, S. y Bodgan, R. (1990). Introducción a los métodos cualitativos de investigación: la búsqueda de significados. Buenos Aires: Paidós.

Varsavsky, Óscar (1969). Ciencia, política y cientificismo. Buenos Aires: Centro Editor de América Latina. 